Recebido: 0 08/09/2021

Publicado: $128 / 12 / 2021$

\title{
O SENTIDO PESSOAL DO TRABALHO VOLUNTÁRIO: UMA ANÁLISE DE RELATOS DE VOLUNTÁRIOS DE UMA INSTITUIÇÃO DE LONGA PERMANÊNCIA PARA IDOSOS
}

\author{
Michelle Aparecida Ferreira dos Santos ${ }^{\mathrm{i}} \odot$ 0000-0003-3647-9837 \\ Centro Universitário Cidade Verde - UNIFCV \\ Zaira Fátima de Rezende Gonzalez Leali ${ }^{\mathrm{i}} \odot$ 0000-0001-5692-4243 \\ Universidade Estadual de Maringá - UEM
}

RESUMO: O seguinte artigo é fruto de uma dissertação de mestrado a qual se objetivou analisar o sentido pessoal do trabalho voluntário. Foi realizada uma pesquisa de campo por meio de entrevistas abertas em uma entidade de acolhimento de longa permanência para idosos do Município de Maringá/PR. Foram realizadas entrevistas com seis voluntários, e observamos que os motivos que instigam os sujeitos a realizarem a ação voluntária estão ligados intrinsecamente a questões históricas, culturais e econômicas, que por sua vez são permeadas por contradições, nexos e múltiplas determinações. As categorias de análise levantadas a partir das respostas comuns foram: a empatia; o voluntariado enquanto um espaço de trabalho; o ganho pessoal obtido pelo trabalho voluntário e o voluntariado justificado pela espiritualidade e/ou religiosidade.

PALAVRAS-CHAVE: Voluntariado. Capitalismo. Psicologia histórico-cultural.

\section{THE PERSONAL MEANING OF VOLUNTEER WORK: AN ANALYSIS OF VOLUNTEER REPORTS FROM A LONG-TERM CARE INSTITUTION FOR THE ELDERLY}

\begin{abstract}
In society governed by Capital where social relations are marked by individualism, there is a type of action that points towards the contradiction: volunteering in the third sector. The following article is the result of a master's degree dissertation which aimed to analyze the personal meaning of volunteer work. A field survey was conducted through open interviews in a long-term care institution for the elderly in the municipality of Maringá / PR. Interviews were conducted with six volunteers, and we observed that the motives that instigate subjects to perform voluntary action are intrinsically linked to historical, cultural and economic issues, which in turn are permeated by contradictions, nexus and multiple determinations.
\end{abstract}

The categories of analysis drawn from the common responses were: empathy; volunteering as a work space; the personal gain obtained by voluntary work and volunteerism justified by spirituality and / or religiosity.

KEYWORDS: Volunteering. Capitalism. Historical-Cultural Psychology. 


\section{Introdução}

A história do trabalho voluntário no Brasil é muito antiga e também muito incentivada. Em uma sociedade capitalista em que tempo e dinheiro são prioridades, contraditoriamente surge uma prática que além de não remunerada, atrai pessoas que se responsabilizam por uma intervenção que deveria ser dever do Estado.

Segundo a pesquisa quantitativa do IBOPE realizada em 2011, 25\% da população brasileira declara que faz ou fez serviço voluntário; destes, $87 \%$ declaram estar motivados com o trabalho, $10 \%$ declaram-se neutros e apenas $2 \%$ se declaram desmotivados.

Por meio da Psicologia Histórico-cultural e da reflexão filosófica marxista encontramos os subsídios necessários para fundamentar o objeto de estudo para a compreensão do mesmo. Desta forma, partindo da base epistemológica do materialismo histórico-dialético e da psicologia histórico-cultural se objetivará analisar e compreender o objeto de pesquisa, o trabalho voluntário.

Inicialmente trouxemos uma explanação sobre o sentido e significado para melhor explicitarmos nas análises sobre as motivações desta ação voluntária. Na sequência, apresentamos um resumo sobre a história do voluntariado no Brasil e sua ação vinculada à assistência social e ao terceiro setor. Por fim, a pesquisa, seus procedimentos metodológicos e os dados obtidos por meio de uma pesquisa de campo realizada na entidade de acolhimento de longa permanência 'Lar dos Velhinhos', por meio de entrevistas com seis voluntários, seguida da transcrição e análise dos discursos colhidos para compreender o sentido pessoal desta atividade segundo a Psicologia Histórico-cultural.

A análise de nosso objeto de estudo está ligada a uma história que não é linear, mas permeada por suas contradições e múltiplas determinações que culminaram naquilo que socialmente se estabelece hoje como voluntariado. Considerando que o presente estudo objetiva investigar o sentido do trabalho voluntário nas instituições de terceiro setor, discorreremos primeiramente sobre os conceitos de sentido e significado, a partir da Psicologia Histórico-Cultural e sua correlação com a temática da pesquisa.

\section{Os conceitos de significado social e do sentido pessoal e o voluntariado}

Visando compreender o sentido da realização do trabalho voluntário para o sujeito, buscaremos abordar brevemente os conceitos de sentido e significado a partir da Psicologia Histórico-Cultural, a base teórica de fundamentação desta pesquisa. 
Para Leontiev (2004) a significação social ou significado "é aquilo que num objeto ou fenômeno se descobre objetivamente num sistema de ligações, de interações e de relações objetivas. Para o autor o significado social está ligado diretamente a construção histórica da humanidade, aquilo que foi acumulado e construído por meio das relações entre os homens ao longo dos tempos bem como as diferentes práticas sociais desenvolvidas no decurso desse processo. Desta maneira, o indivíduo ao nascer já está imerso em um sistema de significações do qual ele se apropria ao longo de seu desenvolvimento, fazendo parte de seu processo de humanização.

O sentido da palavra está ligado a tudo que ela provoca na consciência do indivíduo. Leontiev (2004) por sua vez, vai se apropriar deste mesmo conceito, e nomeá-lo como "sentido pessoal", ligado exclusivamente a atividade e a consciência humana. Leontiev (2004, p. 104) aponta que "Todo o sentido é sentido de qualquer coisa. Não há sentidos "puros". Razão por que, subjetivamente, o sentido faz de certa maneira parte integrante do conteúdo da consciência e parece entrar na significação objetiva."

Leontiev (1978) destaca que é por meio da atividade que há relação entre sujeito e objeto e que ele pode se tornar subjetivo pela internalização do mesmo. Ou seja, o conjunto de ações precisa ter coerência com o motivo da atividade para que esta aconteça de modo favorável. É preciso relacionar a ação com o motivo da atividade, o que consequentemente lhe dará sentido. As atividades estão contidas nas relações sociais e elas são orientadas e reguladas pela necessidade. A necessidade, por sua vez, quando objetivada, torna-se motivo.

Em geral a atividade é conduzida por um motivo, o qual está ligado a uma necessidade. Partindo de um sentido materialista-histórico, o autor discorre que as necessidades humanas são produzidas. As necessidades não partem de si mesmas, mas existem a partir de seu conteúdo objetivo. Leontiev (1978) ressalta sobre a importância em aceitar a natureza sócio-histórica das necessidades humanas, pois algumas são manifestadas socialmente e outras biologicamente. As necessidades manifestadas biologicamente são aquelas comuns em animais e humanos, como por exemplo, o ato de alimentar-se. A necessidade de comer do ser humano se diferencia da do animal, pois este muitas vezes se alimenta mediante necessidades determinadas socialmente, o que para o animal apenas são determinadas biologicamente.

Ou seja, para compreender o sentido pessoal de uma atividade é preciso analisar a priori o seu motivo. A apropriação do objeto para o sujeito dependerá do sentido da atividade para o mesmo. Para que a ação tenha o seu sentido é preciso que a sua finalidade vá ao encontro do motivo da atividade. 
O sentido pessoal é o fruto da relação entre o sujeito e objeto, em que no processo de apropriação dos significados atribui o sentido que lhe é particular influenciado por sua forma de sentir, agir e pensar. A consciência necessita dos sentidos pessoais, o que nos leva a entender que durante a apropriação da linguagem, cada sujeito faz de uma forma diferente.

Ou seja, retomando o enfoque da seguinte pesquisa, o trabalho voluntário para o sujeito dependerá do sentido que esta atividade tem para o mesmo e, antes disso, o que motiva a ação. Como pratica, onde, com que frequência, em que circunstâncias, se existe um planejamento anterior, se existe uma reflexão posterior etc. Qual o lugar estrutural que esta atividade ocupa para este sujeito e o que é apreendido a partir dela?

Além disso, podemos concluir que a atividade do voluntariado terá o seu sentido se esta estiver conectada aos motivos do sujeito e não como uma obrigação imposta ou uma simples reprodução de uma prática.

Para proceder à análise do objeto, realizamos um resgate histórico do mesmo e dos fatos ligados a esta história em que observamos que a assistência social, a origem das entidades do terceiro setor (ONGs) e o trabalho voluntário caminharam juntos.

De modo geral, a ação voluntária emerge dos problemas sociais advindos de um determinado momento histórico, porém, o perfil foi se modificando ao longo dos anos. Segundo Borba (2001), no período colonial a caridade era desempenhada no Brasil individualmente e com intuito religioso, afinal não havia culpa pelas diferenças sociais estabelecidas, pois a pobreza era nivelada como pecado.

Faleiros (2011) destaca que em 1498 foi fundada a primeira Santa Casa de Misericórdia em Lisboa por um grupo de leigos e um frade. No ano de 1543, segundo Montaño (2008), podemos destacar a criação da primeira entidade do país para atender desamparados, a Irmandade da Misericórdia, instalada na capitania de São Vicente.

Cabe ressaltar que segundo Gastaldo e Meyer (1989), o hospital da Idade Média era caracterizado como local de exclusão, onde as pessoas que lá trabalhavam buscavam sua salvação eterna por meio da caridade. Nessa compreensão, as autoras enfatizam que a história da própria profissão da enfermagem vem carregada por um aspecto moral e de gênero muito marcante. Primeiramente a questão da predominância feminina na profissão, sendo o cuidado à saúde ligado a uma responsabilidade da mulher. Outra questão destacada foi que as mulheres que prestaram pela primeira vez os seus cuidados aos doentes enquanto trabalho remunerado foram: "bêbadas, desqualificadas e prostitutas" (GASTALDO \& MEYER, 1989, p. 7). 
Após a Primeira Guerra Mundial, e na sequência, com a crise de 1929, houve um aumento do desemprego, dentre outras dificuldades, passando o Estado a intervir na economia para superação e manutenção do capitalismo e investindo em políticas sociais. Segundo Fagundes (2006), é neste cenário que a teoria keynesiana ganha forma, com a política de pleno emprego, tendo como objetivo aumentar as taxas de produtividade para elevar o consumo e a redistribuição de renda: " [...] o Estado deveria intervir no mercado contrapondose ao desemprego e aumentando a produção, dando, dessa forma, suporte para a constituição do Estado de Bem-Estar ou Welfare State” (FAGUNDES, 2006, p. 89). Expande-se então o chamado Estado de Bem-Estar Social para defesa e promoção social.

Conforme destaca Cisne (2004), a criação da Legião Brasileira de Assistência (LBA) deu-se na presidência de Vargas, em 1942, para atender as famílias em que os seus mantenedores (chefes da casa) estavam envolvidos com questões da Segunda Guerra Mundial. A partir deste atendimento voltado às famílias dos convocados, gradativamente a atuação da LBA passou a se expandir para todas as áreas, em sua origem suprindo as necessidades básicas e gradativamente para uma ação mais duradoura. A primeira dama Darcy Vargas foi a primeira presidenta da LBA e, na sequência, fundamentada por meio de estatuto, sucessivamente seria liderada pelas primeiras damas da República brasileira o chamado primeiro-damismo.

Cisne (2004) também relata que diante destas mudanças e demandas surge o Serviço Social, com a implementação de políticas sociais para atender as classes exploradas e manter o controle e a reprodução do capital. Superar as desigualdades sociais não era o compromisso deste modelo de assistência, mas apenas apaziguar os ânimos evitando os conflitos sociais. Neste contexto, sua origem está atrelada à história da assistência e também ligada a uma profissão feminina. Percebe-se que a mulher assumir este papel social está vinculado ao papel doméstico e familiar estabelecido até então.

Passos (2015) destaca em sua pesquisa que durante o período da ditadura militar (1964-1985), houve uma crescente mudança da política de assistência social visando legitimar o Governo e ganhar apoio da população. Percebe-se, assim, que ao longo da história, as legislações também passam a se alterar na busca da garantia destes direitos, mas por trás disso, garantir que haja manutenção deste sistema. Observamos dessa maneira que o grande intuito era garantir um mínimo de assistência para a população aceitar o Governo, mas não a ponto de abalar a ordem econômica e principalmente abalar o Governo Ditatorial.

A Constituição Federal de 1988 foi o impulsionador gradativo da regulamentação embasada na democracia e nos direitos sociais, sendo que a Assistência Social foi inscrita no 
campo de direitos sociais de responsabilidade do Estado. Neste cenário, houve um aumento da população em situação de vulnerabilidade social, surgindo novas figuras preocupadas e comprometidas com a superação de toda esta situação, incluindo os movimentos sociais, associações civis, ONG's (organizações não-governamentais), entre outros, que exigiam do setor assistencial práticas inovadoras para responder a esta demanda, focada em uma política social mais ampla, que acarretou em discussões sobre possíveis caminhos para sua concretização, vinculada ao direito a seguridade social. Cabe ressaltar que tais políticas sociais mais amplas, apesar de se tratarem de conquistas, passam também a atender aos interesses do próprio capital.

Torres (2013) destaca que no ano de 1999, por meio da Lei 9790/99 se cria uma nova modalidade de instituições privadas sem fins lucrativos denominada Organização da Sociedade Civil de Interesse Público (OSCIP). Para obter esta qualificação como OSCIP, a instituição devia se adequar nas normas designadas na legislação que implicavam no repasse de recursos públicos que podiam afetar a forma de funcionamento e até mesmo a estrutura da entidade. Porém, obter a qualificação não significa receber os recursos automaticamente. É necessário que esta entidade firme parceria com o poder Público para assim ter "o vínculo de cooperação entre as partes, para o fomento e a execução das atividades de interesse público, previstas na Lei" (TORRES, 2013, p. 130). A instituição formada pela sociedade civil passa a ser "parceira" deste sistema na medida em que depende financeiramente deste, mantendo o status quo.

Desta forma, percebemos as inúmeras contradições e interesses na manutenção de tais instituições que não conseguem abarcar todos os problemas sociais ocasionados pelo atual modo de produção tampouco amenizá-los. As mazelas sociais continuam aumentando em larga escala e a população, por meio destas organizações, se encarregando de tal responsabilidade.

\section{A pesquisa: Percurso teórico e metodológico}

Visando compreender o sentido pessoal da ação voluntária, buscou-se realizar uma análise por meio do suporte teórico da Psicologia Histórico-Cultural a qual possui embasamento filosófico do método materialista histórico-dialético.

Acreditamos que tal embasamento nos possibilita refletir sobre o nosso objeto de estudo para além da aparência não tornando a pesquisa vazia em si mesma. Desta forma, ao retornarmos ao objetivo principal desta pesquisa, verificamos, partindo deste referencial 
teórico, que não basta analisar os relatos dos voluntários observando apenas os discursos recolhidos, mas que se deve compreender as motivações dos indivíduos para ação voluntária considerando uma análise histórica, cultural e social das múltiplas determinações e nexos envolvidos.

A presente pesquisa foi realizada por meio de uma revisão bibliográfica, análise documental e entrevistas. A revisão bibliográfica se norteou a partir de leituras de livros, artigos, teses, enfim, materiais que contribuíram para fundamentar e analisar os resultados. A análise documental se realizou com as fichas cadastrais dos voluntários, além do estatuto social contendo o histórico da entidade Lar dos Velhinhos. A pesquisa de campo foi realizada inicialmente por meio de um levantamento de dados encontrados nas fichas de voluntários atuantes na entidade de terceiro setor denominada Lar dos Velhinhos do município de Maringá-PR.

As fichas dos voluntários foram escolhidas aleatoriamente, em seguida, realizamos um contato com os voluntários em atividade para ver a disponibilidade de agendamento. Para garantir o anonimato dos entrevistados nomeamos os mesmos como E1, E2, E3, E4, E5 e E6.

Utilizou-se uma entrevista aberta para a coleta das informações necessárias sobre o trabalho dos voluntários para que os pesquisados tenham o máximo de liberdade de expor o assunto a ser investigado. Os materiais utilizados para a realização da pesquisa de campo e coleta de dados foram: Documento de anuência da instituição; Termo de consentimento livre e esclarecido; Roteiro de Entrevista e Gravador.

Depois de coletados os dados, eles foram tabulados para melhor visualização para a produção do perfil dos voluntários, seguido de uma análise qualitativa sobre os relatos dos voluntários, com intuito de compreender a essência deste trabalho para o voluntário e os sentimentos gerados a partir deste. Por envolver pesquisa com seres humanos, esta passou anteriormente pelo comitê de ética (CAAE 63778317.0.0000.0104).

Visando identificar o sentido pessoal da ação voluntária para quem o pratica, elaboramos um roteiro de entrevista que buscasse obter do entrevistado as informações necessárias para esta pesquisa, sendo elas: idade; sexo; se trabalha com outra atividade; o tempo de voluntariado; como começou; se gosta de realizar este trabalho; se encontra dificuldades em realizar essa atividade; o que o motiva; se obtém gratificações; se o entrevistado considera importante o voluntariado; que tipos de contribuição esta atividade lhe traz; o que sente a partir desta ação voluntária e se acredita que o trabalho voluntário acrescenta algo a sua vida. 
DOI 10.33872/revcontrad.v2n2.e021 | v. 2, n. 2 | Jul./Dez. 2021

A apresentação dos resultados foi elaborada a partir de um agrupamento de dados comuns recolhidos dos entrevistados, onde elegemos categorias de análise análogas.

\section{Resultados e discussões}

Observamos primeiramente que dos seis entrevistados apenas um era do sexo masculino, visto que a maioria das pessoas cadastradas para esta atividade na instituição é do sexo feminino. $\mathrm{O}$ dado nos remete a um fato observado historicamente, percebendo-se um grande envolvimento das mulheres na questão social. Identificamos que as mulheres ocupam este espaço de trabalho social e o fato não é uma característica atual, mas fruto de uma construção histórica, onde a mulher assume o papel de cuidadora inclusive das questões sociais.

Outro dado levantado nas entrevistas foi em relação a faixa etária dos voluntários. As idades variam entre 35 e 58 anos, sendo apenas uma com 35 anos e os demais acima de 42 anos, ou seja, entre a idade adulta já antecedendo a terceira idade. Ao se aproximar de uma idade mais avançada, os indivíduos passam a reorganizar seus planos de vida buscando novos espaços de atuação e motivações, o que levanta a hipótese da procura da ação voluntária nesta idade. "Após o afastamento da ocupação laboral e com a realidade da aposentadoria, é preciso, portanto, ressignificar os planos e projetos de vida, a ocupação do tempo livre e as motivações a essa nova condição socialmente imposta.” (KUNZLER, 2009, p. 69).

Cinco entrevistados realizam outra atividade fora o trabalho voluntário e apenas um dedica-se apenas a este trabalho. Acreditamos que a prática deste tipo de atividade proporciona ao indivíduo ganhos pessoais que não seriam alcançados por outros meios. As pessoas acabam buscando outros espaços para atuarem satisfazendo as lacunas que o capitalismo não permite preencher. "A atuação voluntária parece preencher tais lacunas, permitindo àqueles que se envolvem nesse movimento encontrarem diversos níveis de satisfação de suas necessidades individuais" (CALDANA \& FIGUEIREDO, 2008, p. 472).

Em relação ao tempo de voluntariado, uma realiza a atividade a menos de um ano, outro de um a dois anos, três entrevistados de dois a três anos e apenas uma a dez anos. Percebemos por estas informações que a ação voluntária não é momentânea, mas é realizada por um período considerável e mesmo assim traz benefícios que não a remuneração pelo trabalho, mas que a própria atividade traz consigo satisfações pessoais para estes indivíduos. 
Uma categoria de análise agrupada foi em relação a motivação estar ligada a uma preocupação com o outro. Quando questionados sobre o motivo que os levou a iniciar este tipo de trabalho, alguns dos discursos de destaque encontrados em comum se voltavam para uma disponibilidade em ajudar, cuidar, somar e em dedicar um tempo ao outro. Percebemos que há uma motivação inicial para realização desta atividade que parte de uma preocupação com o usuário do serviço, com a constatação que este necessita de um tempo, de carinho e de cuidado que pode ser oferecido pelo voluntário.

Percebemos diante desses relatos a motivação da ação pela necessidade do outro em carecer de afeto, cuidado e atenção. A grande maioria dos idosos institucionalizados se encontra com os laços familiares já rompidos, recebendo pouca ou até mesmo nenhuma visita de seus entes. $\mathrm{O}$ voluntário passa então a ver a sua atividade motivada a partir da necessidade do público atendido, mas não há questionamento sobre a omissão do Estado diante das mazelas sociais enquanto direito que deveria ser garantido.

A grande questão, portanto, a ser observada é que estas ações não devem vir para substituir o dever do Estado. O voluntariado é importante para resgatar nos indivíduos valores humanos que, pela ordem capitalista, nos são capturados, como a importância da empatia e superação da visão individualista próprias do sistema vigente.

Em apenas uma das respostas dos entrevistados houve referência ao sistema vigente, ressaltando o voluntariado na contramão desta lógica. Porém, não se faz alusão a luta de classes, tampouco a responsabilização do Estado quando questionado sobre a importância do trabalho realizado. Nessa fala, traz uma reflexão sobre a contradição do trabalho voluntário que dá ao sujeito outros tipos de gratificações que não o dinheiro, tão almejado no capitalismo. O entrevistado destaca sobre o carinho, amor, solidariedade e afeto como valores recebidos pelo público atendido a quem pratica o voluntariado.

A questão fundamental nesta preocupação com o outro é que se deveria ir além de uma superficial observação acerca de necessidades básicas do público atendido. Não é um carinho e uma atenção em um "tempo livre" de uma pessoa que se dispõe a ir à instituição "arejar a cabeça" que fará a diferença social. Nota-se que muitas vezes, o trabalho voluntário alivia a culpa, sustentada por uma moral cristã, de que quem tem deve dar ao outro, pois do contrário estaria pecando contra Deus, estaria sendo egoísta e não estaria vendo a dificuldade de seu irmão. Percebemos que os voluntários não enxergam que a atuação voluntária é pontual e que a assistência ao público é de dever do Estado e direito do idoso atendido pela ILPI. 
Montaño (2014) destaca que as demandas sociais acabam sendo contestadas seja pelo próprio sujeito que carece da ajuda, seja pela ação de entidades sociais e pelos serviços privados ou por parte da população que se mobiliza pela causa. As pessoas passam a se responsabilizar pelo outro na lógica em que aquele que tem deve dividir com quem não tem, porém, não há uma análise de que há um grande percentual de impostos arrecadados pelo Estado, pagos pela população, que deveriam ser utilizados para realizar a administração de serviços públicos.

O voluntariado deve ser visto para além da benfeitoria e do status que o sujeito acaba adquirindo divulgando este tipo de iniciativa. Existem interesses pessoais, políticos e econômicos nesta ação que não podem ser ignorados. Não se trata de desconsiderar qualquer tipo de ação social por parte da sociedade civil, mas trata-se de olhar além, de buscar uma reflexão crítica desta prática, sem perder o foco na busca pela coletividade, empatia e principalmente na responsabilidade do Estado pela política de assistência social.

Outro aspecto evidenciado nas entrevistas foi a comparação do ambiente institucional da ILPI com um ambiente de trabalho. Porém, neste trabalho voluntário não há responsabilidades, cobranças e o clima é harmonioso e agradável.

Este local contrasta com os demais ambientes de trabalho que são equivalentes ao mundo capitalista, em que a competitividade, cobrança e individualidade são tão comuns. "A lógica de sustentação da atividade voluntária passa pelo fato de esta ser uma ação possível dentro do sistema do Capital, realizando necessidades de estima que talvez o trabalho em uma empresa capitalista não proporcione”. (CALDANA \& FIGUEIREDO, 2008, p. 473)

Percebemos que os entrevistados trazem estas características de modo muito positivo, classificando o voluntariado como uma atividade sem cobrança e sem obrigação, o que nos faz refletir sobre a qualidade do serviço oferecido e comprometimento afetivo deste com o público atendido, que muitas vezes espera sua companhia, mas pode não desfrutá-la devido a esta falta de comprometimento. Também se pode pensar que o indivíduo necessite realizar uma atividade considerada socialmente útil, fora do ambiente doméstico, mas, ao mesmo tempo, se ressente da responsabilidade e cobrança normais na atividade de trabalho remunerado.

Outro fato evidenciado é em relação ao ganho de experiência profissional que a atividade voluntária pode proporcionar à pessoa que o pratica, pois no mercado formal de trabalho não encontra oportunidade, esta adquire experiência profissional para sua formação por meio do voluntariado dentro da instituição. Dessa forma, observamos uma exploração do trabalho do voluntário pela instituição, e da instituição pelo voluntário, em que o trabalho é 
feito para benefício próprio e não do outro, embora no discurso seja pelo outro. Também a instituição se aproveita da cultura do trabalho voluntário e da necessidade do voluntário em, muitas vezes adquirir experiência, para utilizar essa mão de obra gratuita e deixar de gastar com a contratação de pessoal qualificado. Este fato foi evidenciado em um dos relatos, em que o voluntário em questão adquiriu experiência e passou a dar valor ao seu trabalho a partir da realização de atividades voluntária como enfermeira. A oportunidade de ser voluntária da área de saúde proporcionou mais experiência e consequentemente gerou uma autovalorização do seu trabalho. Realizar esta atividade na instituição tinha o seu destaque pela importância dos cuidados voltados à área da saúde ao público atendido.

Há uma busca pelo bem-estar e diminuição de angústias geradas pelo capitalismo, porém, não há um embate efetivo com o sistema. Os indivíduos encontram nestes espaços do chamado Terceiro Setor um conforto e uma atenção não recebida em um espaço de trabalho formal, em que existem cobranças, competição, desvalorização, entre outros pontos negativos. "[...] a realização da atividade voluntária atua para aliviar as tensões determinadas pelo sistema do Capital, sem, contudo, se contrapor ou alterar tal sistema" (CALDANA \& FIGUEIREDO, 2008, p. 473). Na atualidade o trabalho em si não é mais um meio de satisfação, pois aquilo que se utiliza para satisfazer as necessidades dos homens é o seu resultado final, no caso o salário. O espaço das instituições sociais ganha força na medida em que "ocupa" uma parcela da atividade em ações de voluntariado.

Ao iniciar a pesquisa, acreditávamos que parte dos entrevistados poderiam trazer a busca pelo voluntariado como uma preocupação social particular, mas também esperávamos relatos individualistas, onde a grande motivação da ação seria de cunho particular, ou seja, no prazer pessoal de quem realiza.

Apreendemos diante dos relatos trazidos pelos entrevistados que a ação voluntária traz uma grande satisfação pessoal para quem pratica a atividade. A ação voluntária por parte de quem pratica a atividade proporciona um bem-estar, observado a partir dos relatos dos entrevistados. Ou seja, ser voluntário em uma instituição tem mais relação com o próprio sujeito, com sua satisfação pessoal, seu reconhecimento pessoal como pessoa boa, altruísta, do que com o benefício ao outro, àquele que necessita de atenção e afeto.

O "coração ficar cheio" mostra a sensação de alívio que o voluntariado é capaz de proporcionar à pessoa que realiza a ação, como espécie de missão cumprida. Foram diversos os discursos retirados das entrevistas em que observamos esta característica de individualismo por parte do voluntário. Como se a realização fosse apenas gerar este sentimento de prazer e não a ajuda em si. 
Percebemos que o fato de ser voluntário engrandece a forma em que o sujeito se enxerga proporcionando-lhe satisfação pessoal, ligando a ajuda ao prazer pessoal. Este passa a acreditar que é uma pessoa melhor trazendo um sentimento de alívio, como se estivesse cumprindo seu o dever no mundo.

O auxílio ao próximo fica diretamente ligado ao fato de sentir-se bem e não nos reflexos positivos que deveria alcançar o usuário do serviço. "Fica evidenciada em diversos relatos a complexidade da relação altruísmo-egoísmo. Tal relação indica que a ajuda pode até mesmo ser prejudicial, pois quem a recebe não define as bases dessa ajuda e pode também se tornar dependente da mesma" (CALDANA \& FIGUEIREDO, 2008, p. 477). Percebemos o caráter individualista nos relatos, próprio da sociedade capitalista, em que o prazer e a sensação de bem-estar está vinculada a quem pratica a ação, não havendo reflexão se quem recebe está a favor ou não, se está sendo efetivo ou não. Um dos entrevistados relatou que relatou que a atividade a ajudou a superar uma fase de luto muito difícil, recebendo carinho na medida em que dispôs seu tempo ao voluntariado. Percebemos que as carências dos sujeitos entrevistados passam a ser supridas na realização da atividade na entidade, o que mostra os benefícios trazidos para aqueles que fornecem a ajuda. Mas é preciso analisar criticamente, pois, "[...] da maneira em que está estruturado atualmente, ou seja, como elemento fundamental à ordem capitalista, tem gerado mais benefícios àqueles que fornecem a ajuda do que àqueles que a recebem, faz-se necessário analisar cuidadosamente essa 'dialética da ajuda"” (CALDANA \& FIGUEIREDO, 2008, pp. 476-477).

Realizar a ação voluntária por uma satisfação pessoal, retira do sujeito atendido o direito de ser ajudado em sua integralidade, dignidade e com a qualidade devida conforme lhe deveria ser garantido. "Esses ganhos percebidos podem sustentar a continuidade das atividades voluntárias e manter a clássica lógica vigente no voluntariado que, muitas vezes, é autoritária e não considera o ponto de vista dos ajudados" (CALDANA \& FIGUEIREDO, 2008, p. 477).

Há uma perversão da lógica, pois a doação que acompanharia o serviço voluntário em instituições se torna benefício pessoal. Não se doa aquilo que o outro precisa, valorizando a necessidade do outro, mas se doa para receber o prêmio da satisfação pessoal, da 'alma' aplacada, por se mostrar altruísta, boa. A mensagem é "olha como sou uma pessoa boa, como ajudo os outros sem receber nada em troca". Parece ser esta a motivação, quer dizer, novamente não é a preocupação com o outro, mas consigo próprio. É uma ação egoísta e descompromissada. 
Outro ponto em comum relatado pelos entrevistados em relação ao voluntariado foi sobre a religiosidade e/ou espiritualidade. Percebemos, nos relatos, que a gratificação no trabalho realizado também passa a ser uma realização pessoal de espírito, de salvação, de fé e missão de vida na terra.

Notou-se que a atividade realizada na instituição é uma realização divina, onde o sujeito é colocado como instrumento de Deus na terra, utilizado para ajudar o próximo. Conforme observamos historicamente, a religiosidade está vinculada ao ser social na medida em que esta dá sentido ao ser humano, vem para suprir suas necessidades, dando explicações para aquilo que não se esclarece no interior do próprio mundo. Esta espiritualidade acaba por influenciar a própria maneira que o indivíduo tem de enxergar o mundo e agir nele. No caso do voluntariado não é diferente, pois a ação de preocupar-se com o outro vem como o elo entre o homem e Deus, e ao realizar o bem ao próximo estaria realizando a própria vontade do criador.

Realizar-se como ser humano e como filho de Deus a partir desta ação voluntária nos mostra o quanto a religiosidade influencia na prática do bem e no medo do castigo. "A educação, ligada à transmissão de princípios religiosos, promove o fortalecimento da cultura do voluntário e constitui importante elemento de manutenção dessa lógica” (CALDANA \& FIGUEIREDO, 2008, p. 474).

O voluntariado se apresenta como uma prática contraditória ao atual sistema, visto que não há remuneração na realização deste trabalho e há preocupação com o outro, mesmo no auge da individualidade resultante da própria organização social vigente. Um sistema que se organiza pela exploração dos homens, que gera miséria ao produzir riqueza, e que incentiva a competição, também traz a necessidade de cuidar dos desvalidos, olhados em seu aspecto individual e não de constituição social a partir do sistema. Os indivíduos são então colocados como responsáveis pela demanda social gerada pelo próprio sistema por meio do trabalho voluntário em ONGs e afins.

A ação passa a ser gratificante ultrapassando a barreira financeira e individualista, em que a necessidade pessoal para buscar realizar esta prática é a satisfação pessoal e espiritual motivando esta ajuda ao próximo. Pelos relatos a ação voluntária está ligada diretamente a missão de vida na terra, como um elo automático, porém, não há reflexão ou consciência clara sobre a atividade que se realiza, o porquê ou para quem se realiza, mas que apenas é algo positivo, ligado a fé e a missão de vida.

Tonet (2016) destaca que embora a religiosidade se apresente como alienante, esta não pode ser considerada negativa em sua totalidade, pois ela impulsiona o avanço do processo de 
humanização. A propriedade privada traz seus pontos negativos no processo de alienação, mas também impulsiona as forças produtivas, trazendo novas possibilidades para a humanidade.

É preciso compreender que a própria religiosidade não está imune as influências do capital. Apesar de impulsionar os indivíduos a práticas solidárias e humanas, não consegue atingir um olhar revolucionário que busque a transformação social de fato.

Conforme destaca Tonet (2016) é importante superar a visão da religiosidade para poder ter um olhar crítico diante da realidade. É preciso considerar os meios que levam a construção das desigualdades, os seus fundamentos materiais e não apenas desejar um mundo melhor praticando ações pontuais que apenas mascaram esta realidade. "Daí o pacifismo que impregna a ampla maioria dos crentes. Deseja-se um mundo de paz e harmonia, mas rejeitamse os meios que podem levar à sua construção" (TONET, 2016, pp. 96-97).

O que se observa segundo o autor é que há contradições nos discursos, pois a medida em que há defesa do bem comum, também há defesa dos interesses das classes dominantes, pois só de existir a desigualdade de classes implica que há luta entre as mesmas. Desta forma, não deve haver uma luta entre crentes e ateus, mas que haja um pensamento comum e revolucionário pelo fim da propriedade privada.

A mudança ocorre na materialidade, depende da atividade humana, e depositar a vida em um ser transcendente retira do próprio homem a sua capacidade de poder agir de fato sobre esta realidade e modificá-la.

Percebemos diante destes relatos acerca da influência da religiosidade, que as necessidades pessoais a serem satisfeitas estão relacionadas a sua visibilidade enquanto uma boa pessoa; a sua isenção de culpa; a salvação de seu espírito; a tranquilidade da alma e da consciência; o reconhecimento em praticar o bem e preocupar-se com o próximo contribuindo positivamente na sociedade.

De modo geral, compreender o sentido pessoal do trabalho voluntário é, antes de tudo, compreender a sua relação com a atividade realizada e o que motiva esta ação. Percebemos diante das entrevistas realizadas que quatro categorias foram elencadas enquanto grandes motivadores dessa prática, sendo elas: a necessidade do outro, o espaço de trabalho favorável, o ganho pessoal e o alívio espiritual.

De modo geral, compreender o sentido pessoal do trabalho voluntário é, antes de tudo, compreender o significado social desta prática. Conforme destacado anteriormente, observamos que Leontiev (2004), desenvolveu seus estudos acerca da significação relacionando-a ao que os homens constroem em suas relações ao longo dos tempos, a 
DOI 10.33872/revcontrad.v2n2.e021 | v. 2, n. 2 | Jul./Dez. 2021

consciência individual do sujeito, ligado à sua época, e que no presente assimila as significações anteriormente construídas de forma generalizada e refletida. Ou seja, quando o sujeito nasce já está imerso em um sistema de significações o qual vai se apropriando na medida em que se desenvolve.

Dessa maneira, o conceito do voluntariado está atrelado ao significado social que este possui, ou seja, que ele já está imerso em um sistema de significações o qual o constituiu como tal longo de sua existência. Não conseguiremos enxergar o significado social do voluntariado por ele mesmo, mas em sua totalidade, atrelado a sua história e das múltiplas determinações e contradições. Por isso, a importância dos resgates históricos e de destacarmos o exercício do método materialista histórico-dialético para análise.

Em relação ao sentido do voluntariado, primeiramente realizaremos um breve resgate acerca deste conceito para seguinte análise. Conforme apontado por Vigotsky (2001), o sentido está vinculado a ação humana, ou seja, o que a atividade provoca na consciência do indivíduo. Leontiev (2004) por sua vez, denomina o conceito de "sentido pessoal" ligado a atividade e na relação entre sujeito e objeto, em que este objeto passa a ser subjetivo pelo processo de internalização do mesmo por meio desta relação.

É preciso relacionar a ação com o motivo da atividade, ou seja, a atividade voluntariado com o seu motivo, o que consequentemente lhe dará sentido. Conforme exposto, as atividades estão contidas nas relações sociais e elas são orientadas e reguladas pela necessidade.

O voluntariado integra essas relações e é regulado pela necessidade humana que por sua vez é produzida socialmente e/ou biologicamente. No caso o ato de saciar a fome é caracterizada como biológica, já as necessidades sociais criadas pelo próprio sistema capitalista poderiam ser amenizadas pelo voluntariado na busca de esvaziar os sentimentos negativos gerados por este modo de produção atual, como: solidão, vazio, depressão, inutilidade, culpa, desprazer, dentre outros. Considerando que as necessidades humanas são produzidas, ou seja, que elas não partem de si mesmas, mas existem a partir de seu conteúdo objetivo, percebemos que estas necessidades sociais dos indivíduos não existem ao acaso, mas que são produzidas e correlacionam com a forma de organização social estabelecida.

No que tange ao sentido pessoal do voluntariado, o mesmo é o resultado da relação entre o sujeito e objeto, em que no processo de apropriação dos significados (construídos historicamente) atribui o sentido que lhe é particular influenciado por sua forma de sentir, agir e pensar. 
Ou seja, retomando o enfoque da seguinte pesquisa, o trabalho voluntário para o sujeito dependerá do sentido que esta atividade tem para o mesmo e, antes disso, o que motiva a ação e quais as necessidades busca suprir. Como pratica, onde, com que frequência, em quais circunstâncias, se existe um planejamento anterior, se existe uma reflexão posterior etc. Qual o lugar estrutural que esta atividade ocupa para este sujeito e o que é apreendido a partir dela? Quais necessidades esta ação busca suprir?

Além disso, podemos concluir que a atividade do voluntariado terá o seu sentido se esta estiver conectada aos motivos do sujeito, e não como uma obrigação imposta ou uma simples reprodução de uma prática. Que deve haver um amplo conhecimento acerca do significado social desta prática para que o indivíduo possa partir para realização desta atividade de modo menos alienado, do contrário, este buscará suprir muito mais as suas necessidades do que a do outro que inicialmente se propôs ajudar.

O sentido pessoal, de modo geral, está ligado à sua relação com a atividade realizada e o que motiva esta ação. Partindo para o nosso objeto de estudo, no caso o voluntariado, percebemos diante das entrevistas realizadas que quatro categorias foram elencadas enquanto grandes motivadores dessa prática, sendo elas: a necessidade do outro, o espaço de trabalho favorável, o ganho pessoal e o alívio espiritual.

Concluímos que todas elas, de alguma forma, voltam-se para uma necessidade individual, em que não há reflexões coletivas, reflexões do papel do Estado, e tampouco uma ação que edifique, de fato, uma transformação social. São ações pontuais que amenizam o sentimento de culpa, e que geram satisfação para quem as realiza, sem questionar os impactos para aquele que a recebeu.

\section{Considerações finais}

Partindo da análise histórica explanada no referencial teórico, seguida pela análise das entrevistas, pudemos observar que a sociedade civil organizada passou a assumir um papel que deveria ser do Estado nas ações de voluntariado. Porém, o foco nunca esteve na coletividade, igualdade social, garantia de direitos, ou transformação social, mas na manutenção do status quo, no caso, na sustentação do sistema capitalista.

Percebe-se que os incentivos à prática do voluntariado se fizeram presentes em nossa história em momentos oportunos, ou seja, momentos em que o próprio sistema julga ser viável a prática do trabalho voluntário. Desde o Brasil colônia onde os incentivos se 
baseavam na influência religiosa (onde a Igreja ditava a forma de organização social), até a Constituição de 1988 percebemos os interesses de classes nesta atividade.

Existe uma conformidade com a omissão do Estado e há uma auto responsabilização do indivíduo na prática das ações sociais. É como se tivesse mais valor a ação executada de pessoa para pessoa do que a do Estado, pois aquela seria tida como mais edificadora para o ser humano. O voluntário busca na ação social um meio de satisfação pessoal, uma atividade que lhe permita a concretização de sua missão espiritual e/ou religiosa, que lhe proporcione um comportamento solidário, e que lhe favoreça um ambiente de trabalho positivo e agradável. É como se o atual sistema não preenchesse suas necessidades, e o voluntariado passasse a lhe dar o sentido.

Ao retomar a minha pergunta inicial sobre o sentido pessoal do trabalho voluntário, e partindo da análise teórica seguida pela pesquisa de campo com os entrevistados, percebi que este se relaciona com o significado em um processo de alienação. Conforme observei, o significado social está diretamente ligado à construção histórica da humanidade, tudo o que foi acumulado e construído por meio das relações entre os homens, e as diferentes práticas sociais desenvolvidas no decurso desse processo. O ser humano já nasce em um sistema de significações do qual ele se apropria ao longo de sua vida.

Sendo assim, o significado do voluntariado, conforme observado nesta pesquisa, está atrelado à história da luta de classes, culminando na organização social estabelecida pelo capital e gerando as desigualdades sociais. Essas mazelas sociais, por sua vez, não são supridas pelo Estado, pois este não tem o interesse em combatê-las, passando a sociedade civil a se ocupar dessa responsabilidade, e o Estado em manter a economia.

Dessa forma, o sujeito parte para realização da atividade voluntária de forma alienada, sem consciência real das dimensões dessa atividade e do seu real significado na sociedade capitalista em que se insere.

Ao partir dos resultados colhidos nas entrevistas realizadas, pude observar que cada sujeito possui a sua motivação particular e o seu sentido pessoal para a realização da ação voluntária. O envolvimento das mulheres na questão social foi um dado considerado bastante relevante e historicamente presente, pois dos seis entrevistados apenas um era do sexo masculino, confirmando que o fenômeno não é atual, em que o gênero feminino está vinculado ao cuidado, inclusive, das questões sociais.

Outra informação a salientar na pesquisa, foi a necessidade do outro como motivador da ação voluntária, trazendo o seu sentido pessoal. A partir dos relatos, observei que os voluntários traziam as carências dos usuários do serviço (idosos acolhidos) e de doarem 
tempo, carinho, atenção para suprir essa falta de alguma maneira. Apesar do resgate aos valores humanos nessa superação do individualismo reforçado pelo sistema capitalista, é importante ressaltar que a ação voluntária não deve vir para substituir o dever do Estado.

Também foi possível verificar, por meio deste trabalho de campo, que os voluntários, muitas vezes, colocam o espaço (ambiente da ação) do voluntariado como um espaço de trabalho positivo, sem cobranças e sem responsabilidades. Além disso, é um local em que se pode desenvolver uma atividade considerada útil socialmente, com visibilidade positiva, e isento de algumas cobranças que existiriam em outro emprego remunerado. Ao ser equiparado a um campo de trabalho formal, muitas vezes a instituição aproveita-se desta mãode-obra sem custo para prestar o serviço que deveria ser realizado por alguém devidamente qualificado.

Outro aspecto levantado nas entrevistas realizadas, é que o bem-estar proporcionado pelo autor da ação é muito evidente, não demonstrando uma preocupação com o outro em si (o usuário atendido que deveria receber o benefício), mas no prazer, na sensação de bem-estar proporcionada ao próprio voluntário enquanto motivador de sua ação, ou seja, o sentido pessoal do voluntariado enquanto satisfação própria.

Também concluí, a partir das falas, a relação entre voluntariado e espiritualidade, que a benfeitoria e a caridade são práticas essenciais para garantia da salvação da alma e/ou alívio de consciência. Assim como a religiosidade mantém o sistema capitalista conforme observado, esta se vincula a outras práticas sociais existentes para legitimar esta organização social.

De modo geral, o sentido pessoal do voluntariado está ligado diretamente à atividade $\mathrm{e}$ aos motivos que geram a ação: seja pela necessidade do outro; seja na realização da atividade como espaço de trabalho prazeroso; seja para sua própria realização e prazer; ou para obter alívio do sentimento de culpa gerado pela influência religiosa da caridade. Em todos os casos, a motivação remete de algum modo a um ganho pessoal. A sociedade naturaliza esta (des)reponsabilização do Estado e, havendo este retorno positivo para o sujeito, pouco se questiona sobre o voluntariado em sua essência, e ainda menos sobre a omissão do Estado e as demais contradições apresentadas.

A partir do que está posto (o que foi historicamente construído e da forma atual de organização dos homens em sociedade), e dos dados levantados nesta pesquisa, pude realizar algumas proposições possíveis para que a prática do voluntariado ocorra de maneira mais efetiva e positiva. 
DOI 10.33872/revcontrad.v2n2.e021 | v. 2, n. 2 | Jul./Dez. 2021

As instituições sociais de terceiro setor deveriam estabelecer seus critérios mínimos para o cadastro de seus voluntários, e na sequência capacitá-los e sensibilizá-los para a ação. Para isso, a equipe dessas entidades também deveria estar munida de conhecimentos acerca da história e suas contradições, bem como o papel fundamental do Estado na garantia de direitos. Ao dominarem o conhecimento, essas equipes poderiam esclarecer aos seus voluntários acerca do dever do Estado, sobre o público atendido e suas demandas reais para aí, sim, poderem realizar a atividade dentro da organização social. Dessa maneira, o sujeito realizaria a atividade voluntária de forma menos alienada, com uma maior consciência das dimensões dessa atividade, e do seu real significado na sociedade em que se insere.

É importante reconhecer que qualquer tipo de ação voluntária, seja ela de cunho social ou ambiental, tem o seu impacto positivo ainda que mínimo. Porém, não podemos ser ingênuos acreditando que haverá, de fato, transformação social neste tipo de prática, quando na realidade as mesmas são produtos do próprio sistema vigente.

\section{REFERÊNCIAS:}

BORBA, E. R. L. Terceiro Setor: responsabilidade social e voluntariado. Elisabete Regina de Lima Borba (Org.), Lenyr Rodrigues Borsa \& Roldite Andreatta. Curitiba: Champagnat, 2001.

CALDANA, A. C. F.; FIGUEIREDO, M. A. C. O Voluntariado em questão: a subjetividade permitida. Psicologia, Ciência e Profissão. Brasília, v. 28, n. 3, p. 466-479, 2008. Disponível em <http://www.scielo.br/scielo.php?pid=S1414-98932008000300003\&script=sci_arttext.>. Acesso em: 23 ago. 2015.

CISNE, M. Serviço Social: uma profissão de mulheres para mulheres? Uma análise crítica da categoria de gênero na histórica "feminização" da profissão. Universidade do Estado do Rio Grande do Norte. Recife/PE, 2004. Disponível em: <http://repositorio.ufpe.br/bitstream/handle/123456789/9916/arquivo9102_1.pdf?sequence=1 \&isAllowed=y>. Acesso em: 20 ago. 2017.

FAGUNDES, H. S. As Repercussões do Voluntariado e da Solidariedade nas Políticas Sociais no Brasil. Sociedade em Debate, Pelotas, 12(1): 87-102, jun. 2006. Disponível em: <http://www.rle.ucpel.tche.br/index.php/rsd/article/viewFile/438/392>. Acesso em: 18 nov. 2015.

FALEIROS, E. T. S. A criança e o adolescente. Objetos sem valor no Brasil Colônia e Império. Em: Rizzini e Pilotti (Org.) A arte de governar crianças: a história das políticas sociais, da legislação e da assistência à infância no Brasil. São Paulo: Cortez, 2011.

GASTALDO, D. M.; MEYER, D. E. A formação da enfermeira: ênfase na conduta em detrimento do conhecimento. Rev. bras. enferm. [online]. 1989, vol. 42, n. 1-2-3-4, pp. 7-13. ISSN 0034-7167. Disponível em: < http://dx.doi.org/10.1590/S0034-71671989000100002. >. Acesso em 26 jan. 2018.

KUNZLER, R. B. A ressignificação da vida cotidiana a partir da aposentadoria e do envelhecimento. Tese de Doutorado, Pontifícia Universidade Católica do Rio Grande do Sul, Porto Alegre, RS, Brasil, 2009. Disponível em: 
DOI 10.33872/revcontrad.v2n2.e021 | v. 2, n. 2 | Jul./Dez. 2021

$<$ http://repositorio.pucrs.br/dspace/bitstream/10923/5159/1/000411382-Texto\%2BCompleto0.pdf.>. Acesso em: 16 jul. 2016.

LEONTIEV, A. N. Actividad, conciencia y personalidad. Buenos Aires: Ciências del Hombre, 1978.

LEONTIEV, A. O desenvolvimento do psiquismo. Tradutor Rubens Eduardo Frias. 2. ${ }^{a}$ Ed. São Paulo: Centauro, 2004.

MONTAÑO, C. Terceiro setor e questão Social: crítica ao padrão emergente de intervenção social. $5^{\mathrm{a}}$ ed. São Paulo: Cortez, 2008.

Montaño, C. O Canto da Sereia: crítica à ideologia e aos projetos do "Terceiro Setor". São Paulo: Cortez, 2014.

PASSOS, I. C. Assistência Social no Brasil durante a Ditadura Militar: benefícios e beneficiários. Pôster apresentado no Salão UFRGS 2015. Disponível em: <https://www.lume.ufrgs.br/bitstream/handle/10183/136379/Poster_41243.pdf?sequence=2>. Acesso em: 15 dez. 2017.

TONET, I. Marxismo, religiosidade e emancipação humana. Maceió: Coletivo Veredas, 2016.

TORRES, R. C. L. Terceiro Setor: entre a liberdade e o controle. Bahia: JusPodivm, 2013.

VIGOTSKY, L. S. A construção do pensamento e da linguagem. São Paulo: Martins Fontes, 2001.

\footnotetext{
${ }^{\text {i }}$ Doutoranda em Psicologia (Universidade Estadual de Maringá- 2021) e mestra (2018) e graduada (2011) pela mesma instituição. Pós-graduada em Gestão de Pessoas e Psicologia Organizacional pela Faculdade Cidade Verde (2017); em Gestão e Planejamento de Projetos Sociais pela Unicesumar (2013) e em Tecnologias Aplicadas ao Ensino a Distância (2021). Possui experiência como psicóloga clínica e universitária. Atualmente é professora na disciplina de gestão de Pessoas, e coordenadora do curso de Psicologia no Centro Universitário Cidade Verde (UNIFCV). Email: michellesantos1987@ hotmail.com

ii Possui graduação em Psicologia pela Universidade Estadual de Maringá (1986), mestrado em Educação pela Universidade Estadual Paulista Júlio de Mesquita Filho (1997), doutorado em Psicologia Escolar e do Desenvolvimento Humano pela Universidade de São Paulo (2010) e pós-doutorado em Psicologia pela Universidade Federal de Uberlândia. Atualmente é professora associada do Departamento de Psicologia e do Programa de Pós-Graduação em Psicologia da Universidade Estadual de Maringá e supervisora de estágio em psicologia escolar. Email: zairaleal@yahoo.com.br
} 